\title{
Library evolution, trends and the road ahead from the EBSCO lens
}

\author{
(NFAIS Miles Conrad Memorial Lecture, February 23, 2015) ${ }^{1}$
}

\author{
Tim Collins \\ President and CEO, EBSCO Industries, Inc., 10 Estes Street, Ipswich, MA 01938, USA \\ E-mail: tcollins@ebsco.com
}

\begin{abstract}
Much has changed during my thirty years in the information industry. I will review changes in the areas of end-user experience, business models, library workflow, and competitive landscape and describe what I see as the key drivers behind these changes, focusing on the academic research process. I will share my perspective on the role that EBSCO has played in these changes and the evolution of the marketplace. I will also share my thoughts on some changes that I think we will see in the future.
\end{abstract}

Keywords: EBSCO, library industry, subscription services, research, databases, discovery

\section{Introduction}

Multiple elements shape the trends in our industry, including; evolving end-user expectations, vendor business models, "back-end" administrative workflows, and the players who make up the commercial marketplace. Each of these elements impacts different, yet interrelated areas; product development, product pricing, and - importantly - the ability of libraries to optimally serve their users. This paper captures the essence of the NFAIS presentation on the same topic, with some insights on how we at EBSCO have interpreted library evolution through the decades, see current trends and future opportunity, as well as how we approach our business from an industry perspective. I'll also share some of the fundamental principles that have guided our actions over the years.

EBSCO Information Services is a growth-oriented private company, providing different services and products to libraries as outlined below. EBSCO is a:

- Leading subscription service agent with over two billion dollars in sales to libraries worldwide in journals and databases.

\footnotetext{
${ }^{1}$ This paper is based upon the Miles Conrad Award Lecture that was given at the 2015 NFAIS Annual Conference in Crystal City, VA, USA on February 23, 2015. The Miles Conrad Award was established shortly after the death of NFAIS' first President and one of the original founders, G. Miles Conrad, in order to provide a fitting memorial to his accomplishments. The award has been presented every year since 1968 to an information industry leader who has made significant contributions to the Information Community and who has been a supporter of NFAIS. A complete list of awardees can be accessed on the NFAIS website at http://www.nfais.org/miles-conrad-lectures. The slides related to the presentation are not available.
} 
- Leading online research service provider to institutions with more than four hundred databases via the EBSCOhost platform, which includes over three billion records.

- Aggregator, publisher, and distributor. EBSCO licenses content for more than ninety thousand publications from over fourteen thousand partners and is the leading full-text database provider. The company is also a leading e-book aggregator with more than seven hundred thousand books available. In addition, EBSCO produces Abstracting and Indexing (A\&I) databases, including various H.W. Wilson collections, CINAHL, SportDiscus, America: History \& Life, Historical Abstracts, etc.

- Leading Discovery Service Provider. EBSCO Discovery Service (EDS) is in use at over seven thousand libraries worldwide.

- Leading provider of book selection/purchasing service. EBSCO acquired YBP Library Services (see: http://www.ybp.com/about_ybp.html) in February 2015.

\section{The end-user experience}

\subsection{Evolution of library search}

The end-user experience in search has seen tremendous change in the last three decades. The OPAC (Online Public Access Catalog) emerged in the early 1980s to provide online access to discovery of the library catalog for end-users. The OPAC facilitated search of metadata for print books and journals, and also presented circulation status. Libraries offered a separate search of paper indexes to locate articles within journal issues. Between the mid-1990s and 2010 search became fragmented as many new search tools emerged, including:

- ILS OPACs; provided metadata and status for physical assets.

- Full-text platforms; including good Abstracting \& Indexing databases (A\&I) and full articles (some embargoed). Examples are EBSCOhost, IAC/Gale, UMI/ProQuest.

- Secondary database platforms; Rich A\&I articles and books; Examples are OVID, SilverPlatter, EBSCOhost, Cambridge Scientific Abstracts (CSA).

- A-to-Z listing service; browsing of all journals, by title or package.

- E-journal platform; including current author, abstract, keyword, and articles.

- E-book platform; Includes full-text of books; Examples are NetLibrary, ebrary, MyiLibrary.

While each of these services represented an improvement to the previous method of locating the materials they included, the combination of all of the services together resulted in it being a difficult task to search all materials available in a library. Multiple federated search platforms were created to attempt to address the challenge of electronic content retrieval in libraries. These platforms were generally found to be slow, presented a confusing experience to end-users, and lacked long-term viability due primarily to limitations of the technology at that time. In this period, Google proliferated, creating a user expectation that the library should be able to provide a 'single search' of all content that the library could make available to them.

\subsection{Emergence of discovery}

Discovery services made their initial appearance around 2008 and provide a single search box to the library's entire collection. EBSCO Discovery Service (EDS) became EBSCO's core technology offering 
focusing on meeting the needs of different users. There is a lot to consider in a discovery service, including the user interface, the content that can be incorporated, the relevance and value ranking of content, the ability to tailor the solution for specific research needs, and the ability to use APIs to interoperate with the Integrated Library System (ILS). Importantly, each of these affects the end-user experience. We see EDS as the culmination for EBSCO of more than two decades of work for a company where data, search, retrieval and access are core competencies.

Discovery must cater to different researchers and accomplish a variety of objectives. The general researcher (undergraduate) is different than the sophisticated user (graduate student or advanced researcher). What's more, users today expect a Google-like experience and expect the service to retrieve the most relevant results for every query. Users also want the ability to browse by subject and discipline as well as easily locate "known items" (items they become aware of via different methods/services).

EDS features a very sophisticated relevance-ranking algorithm to deliver the right content to the right users for each search. The interface also facilitates personalization of search results by subject domain and retention of a user's search history. Abstracting \& Indexing services play a critical role in supporting a personalized end-user experience. These services enable the leveraging of abstract/index data within the relevance ranking algorithm, as well as the mapping of terms across multiple thesauri. Of course, in order for data discovery to be successful, the service requires quality metadata; without this metadata, content is not discovered. But metadata in and of itself will not make a discovery service strong. The reality is that while metadata is critical for quality discovery, there is far more to it - from relevance-ranking algorithms and known-item searching to mapping thesauri from specialized indexes to the concepts leveraged by undergrads. In the age of discovery, with billions of potential records to discover, there has never been a time when precision in results has been more critical to the success and perception of the library.

Finally, integration is key. The discovery service must interoperate with other applications in the library's ecosystem to facilitate collaboration across institutions and people. Through interoperability and integration, libraries enjoy improved workflows and enhanced access to research data. It is one thing to provide choice, but it's another to truly optimize that choice and support library decisions - regardless of the vendor they choose. We believe that the future of library services will be one based on interoperable components such that libraries can choose the best of each component in their end-to-end service chain (back-office to end-user) and know that these services will be optimized through vendor partnerships and collaboration. No single vendor has all of the services needed, and no publisher provides all the content. Partnership is critical to supporting library decisions, and those that don't take part could be left behind.

Above all, and perhaps the most important aspect in the advent of discovery, is placing the USER at the forefront of library decisions. In studying library strategic plans, we see that these plans are dominated by goals related to user success. But for years, back-end management systems have dominated the library infrastructure. Discovery services, combined with collections dominated by electronic resources, and the advent of open source services are changing this dynamic. When the focus is on the experience provided to end-users, libraries are positioned to succeed. Of course, librarians remain the most valuable resource in every library. But by building around discovery, we are now in a position to maximize the value of the work that every librarian does, to have a greater direct impact on the user. In the end, library success is about user success.

\subsection{Responding to industry trends}

EBSCO follows certain principles in taking advantage of or influencing industry trends. Foremost, we must identify and eliminate 'solution compromises' that customers are accepting. For example, poor 
linking from secondary databases to full-text databases and e-journal articles was a "solution compromise" before we "improved the solution' by offering secondary and full-text databases on the same platform, with seamless linking from abstracts in the A\&I database to the corresponding article in the full-text database. As we evolve and improve EBSCOhost/EDS, we keep our customer's "wish list" in mind and look for ways to "improve the solution".

When considering the above, "economics" rules. Simply put, we've found that when one offers a slightly better solution for less money, customers buy. However, we see it as being better to offer a significantly-improved solution for the same price. When designing new products or business models, it is critical to insure that all parties have an economic incentive to participate over the long run. Long-term partnerships are more important than short-term gain and interest "alignment" is the key to successful long-term partnerships.

Taking advantage of industry trends means looking at both user behavior and business models and abiding by the principles of improving rather than changing user behavior:

- Eliminate steps to existing processes (e.g., fewer keystrokes).

- Combine existing processes into one process (e.g., link to full-text).

- Don't create products that require dramatic change in user behavior.

- Grow via "evolution not revolution" - through continuous incremental improvement.

\section{Business models}

The growth and expansion of business models enable greater access to materials (multiple users and access points), as well as a larger overall collection. The evolution of business models is in different phases across the content resources that EBSCO makes available, all working (at varying degrees of speed) toward greater accessibility and usability. The content resources and their respective models are as follows:

\section{E-journals}

- From one user to unlimited user model for same price.

- "Print + electronic" phase during transition from print to online.

- From under ten percent electronic in 1998 to over seventy-five percent in 2014, based on orders processed through our Subscription Services Division.

\section{Full-text databases}

- Provide access to journals that libraries could never afford in the past and generate incremental revenue for publishers.

- One-year embargo on small subset of content to protect publishers' current subscription revenue; bringing new content into these aggregated models, which benefits libraries and their end users.

E-packages ("Big Deal" - more for pro-rata less)

- Short-Term

- Additional content made available to users at a lower price point.

- Growth engine for publishers as significant price increase when selling e-package. 
- Long-Term

- Libraries paying for content that often doesn't get used.

- Publishers have nothing left to sell, which results in low growth via price increases and the need to acquire additional journals to generate growth.

\section{E-books}

- E-books sales have increased as there has been some transition from print books, but it has been much less dramatic than the pace of transition with journals

- A key factor in this is that the publishers embraced the unlimited usage model for journals early on, but are just now embracing this model for books. For years, librarians have been able to pay a similar price for an e-journal as a print journal and provide unlimited access to the content of the journal. Multiple users can use the same journal issue at the same time.

- For books, the initial model was "one book, one user", and libraries were asked to pay a higher price for the e-book than the print book with no ability to allow multiple users to use the same book at the same time. Over time, "multiple user models" were added, and now many publishers are embracing unlimited usage models for most of their books. As this model becomes more mainstream, the transition from print to e-books should accelerate.

\subsection{Short-term loan vs. inter library loan (ILL) vs. e-book purchase: Time of experimentation/transition}

Perhaps there is no single model that has grown, come under scrutiny, and then declined as quickly as short-term loan (STL). The positives may be price and speed to access as part of a Patron-Driven Acquisition/Demand-Driven Acquisition (PDA/DDA) program, but the lack of collection building (libraries don't own the book) and decrease in overall spending has put the model under pressure. We've seen this model slowly lose participation from publishers as many no longer support STL for new books. Publishers can't afford to effectively lower the price of their books, which is the impact that STL is having in the market. Figure 1 provides a high level view of STL across the spectrum of "why" the model is used, but also "why" it is declining in availability.

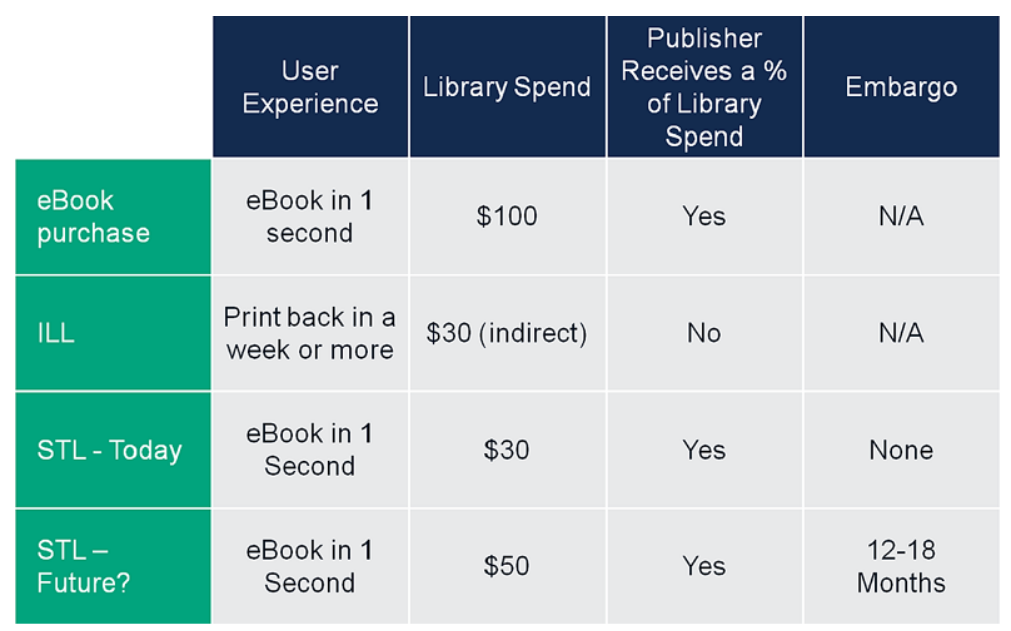

Fig. 1. Short-term loan. (Colors are visible in the online version of the article; http://dx.doi.org/10.3233/ISU-150771.) 


\subsection{Usage as key success driver}

Usage is a key driver of success for online products. We like to say "revenue follows usage". For example, decisions about renewals of journal subscriptions and databases are driven by the actual usage in the prior year. In addition, decisions about book content purchases have, to some extent, have become usage driven via Patron/Demand-Driven Acquisition (PDA/DDA). This model may make sense for some libraries, but in order for it to be sustainable, ways need to be found to ensure that book purchase levels remain constant, so as to avoid large price increases per book that may occur if PDA results in less money being invested in books. The cost of producing a book doesn't go down when unit sales decline, so prices will increase over time as publishers will obviously not able to produce unprofitable books over the long term.

\subsection{Business models for library management systems}

The business models for library management systems are also evolving. With the move away from onpremise to cloud-based solutions, we're moving from an upfront purchase and annual service contract to an annual subscription fee model (Software as a Service - SaaS). We are also moving from Library Management Systems (ILS) that have a forced coupling of discovery with those systems to interoperable sources that allow libraries to choose the ILS and discovery service which they prefer, allowing for optimization of library choice through partnerships. This approach lets libraries evaluate all components and determine what is best for them. When evaluations do not take place, inevitably, concerns and difficulties arise. Now we are seeing this type of choice come to the forefront through recent consolidation of book ordering tools. Companies like EBSCO are working closely with competing vendors to ensure that each library can select its vendor of choice.

\subsection{Library workflows}

Figure 2 illustrates how we see the life-cycle for resource management.

EBSCO is committed to supporting the librarian's information life-cycle from selection through ordering, resource management, discovery, access, and analysis. Figure 3 below highlights the EBSCO product suite across the information life-cycle value chain, after our acquisition of YBP Library Services.

EBSCO has partnered with most major ILS vendors, both proprietary and open source, to facilitate ILS integration within the resource management life-cycle. In fact, while the above is an "EBSCOcentric" view of our proprietary resources in these areas, EBSCO "Open" enables a true collaborative environment and truly supports the resources and technologies that libraries elect to use. We are working to try to avoid the situation where Library A has a strong end-to-end infrastructure because it happened to select the "right" mix of services, while Library B has a less-than-optimized solution because it has a mix of services that may not be optimized due to lack of partnership among the vendors they have selected. Our approach is to encourage vendors to embrace this approach to attain what we must achieve - libraries serving their users successfully. 


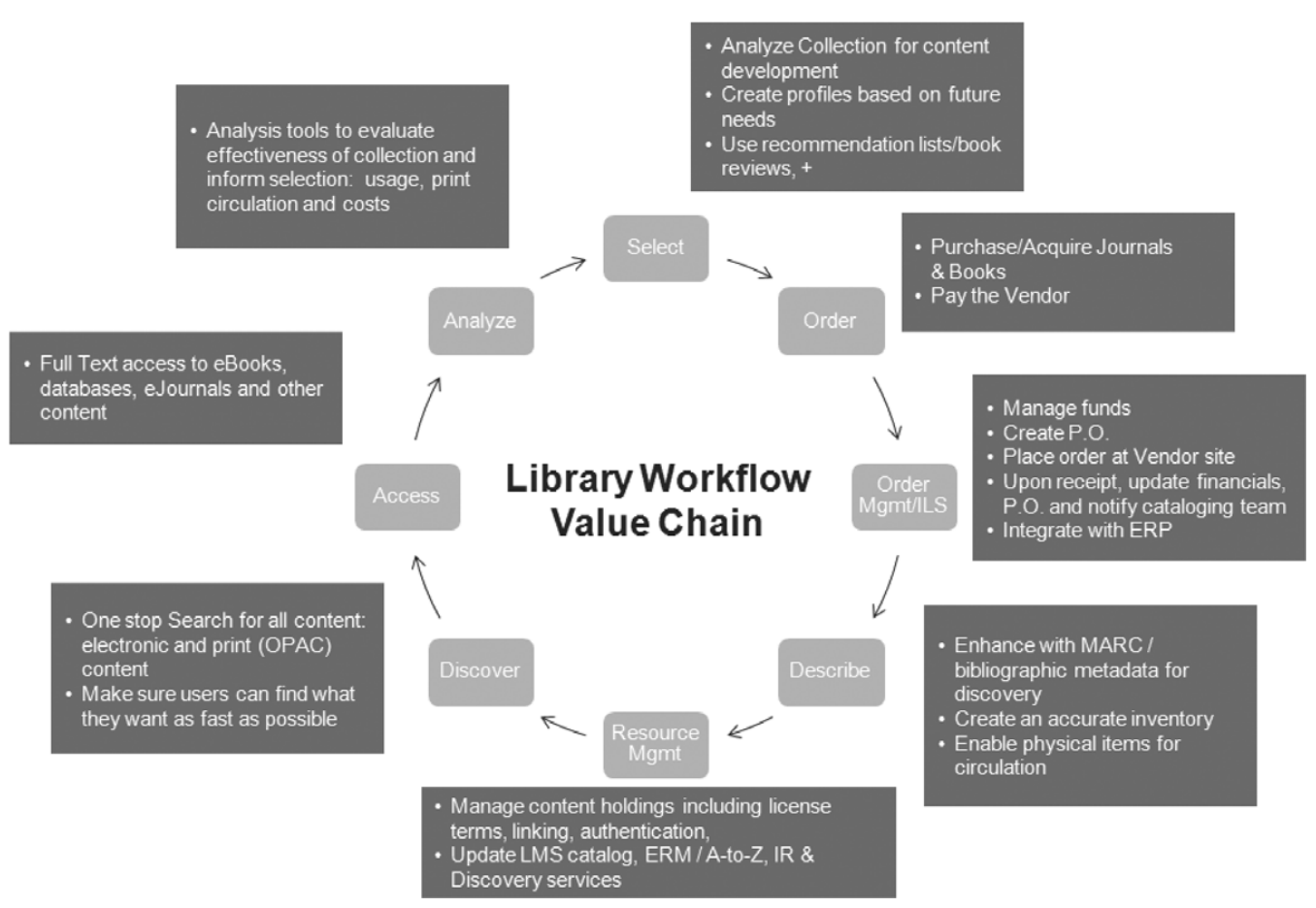

Fig. 2. Library workflow value chain.

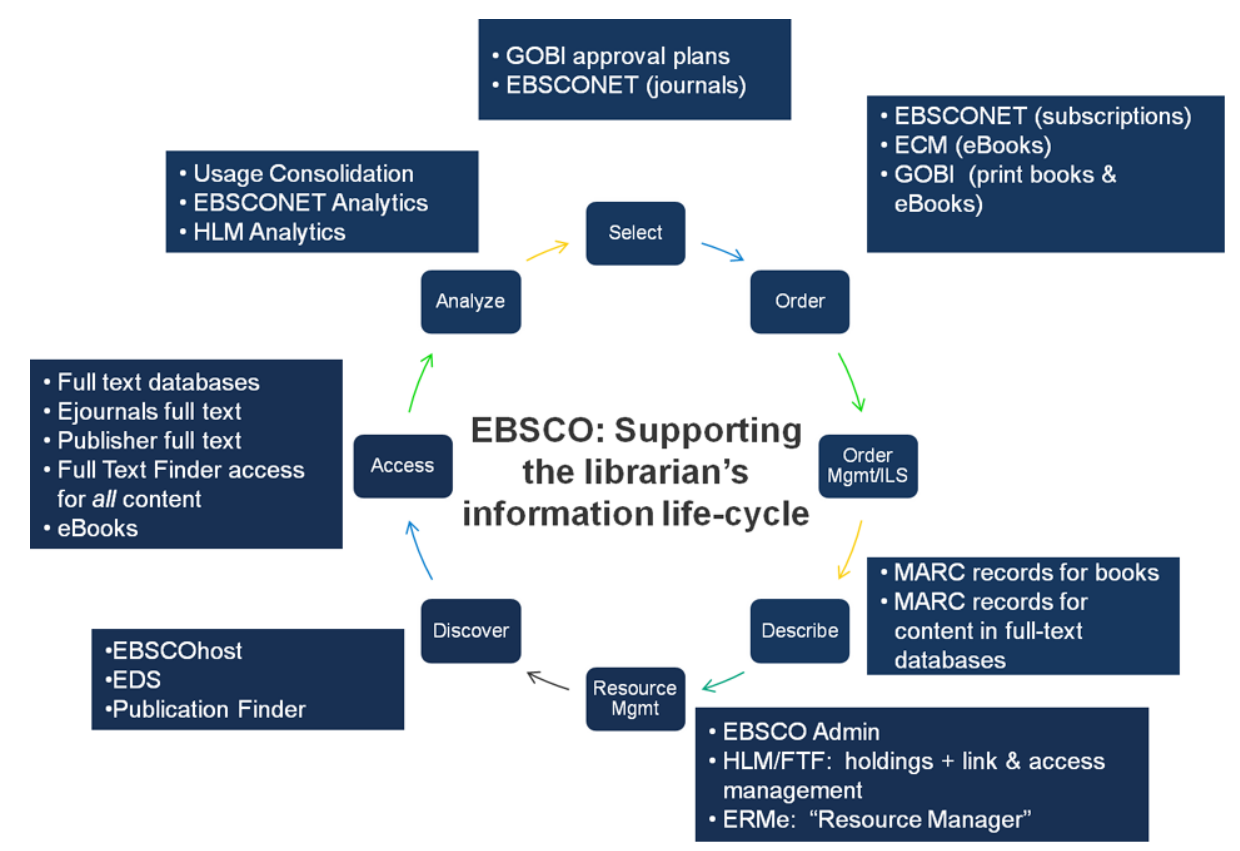

Fig. 3. Information management life-cycle. (Colors are visible in the online version of the article; http://dx.doi.org/10.3233/ ISU-150771.) 


\section{Competitive landscape}

\subsection{Market consolidation}

The market has consolidated over the last thirty years, and this will continue. Consolidation is driven by many factors including economies of scale, technology, merging of functions within the value chain, venture capital, and private equity investments. This trend impacts all players - publishers, database producers, aggregators, agents, library automation vendors.

Many of the larger companies in the library market are owned by private equity firms. We are concerned that this has the potential to stifle innovation if the company becomes more focused on the owner's exit strategy than on innovating for the benefit of libraries.

EBSCO has remained private, striving to maintain its entrepreneurial spirit and focus on innovation while growing. As a private company, EBSCO can focus on "improving the solution" and investing in long-term growth. In the end, no matter what our role is in the library industry (aggregator, publisher, consortium director, individual librarian, etc.), we all want the same thing - to see libraries become not just valued and trusted entities, but to become indispensible. As we approach our decisions, we do so with this idea in mind. This is not an overnight process in most cases. We are grateful that we are a company in a position to take this long-term approach. We are able to re-invest profits back into our business to improve existing products and create new services. It is undoubtedly a luxury for us as EBSCO employees, but moreover for the libraries that we serve.

\subsection{EBSCO principles}

At EBSCO we strive to improve and continue to grow; and, to do so, we ask our employees to abide by the following principles:

(1) Commit to sustained growth.

(2) Have a defined vision and operate with a bias for action.

(3) Be customer-focused and sales-driven.

(4) Understand that change is necessary.

(5) Recognize that you can not Manage what you can not measure.

(6) Foster creativity and continuous improvement.

(7) Insist on quality.

(8) Do what you say you will do.

(9) Cultivate passion.

(10) Realize that business is a long-run game.

(11) Improve the foundation.

(12) Be humble.

EBSCO continues to grow, and as such we are seen, rightfully so, as a large company. But we were certainly not always a big company. The single biggest reason for our success is the people who work for us. We employ hundreds of librarians, technologists, editorial experts, customer support, and many others who care a great deal about what they do. We have become a large company because of the commitment, care, and attention to detail that all of these individuals put into their work. 


\begin{abstract}
About the author
In 1983, Tim co-founded a company specializing in indexing and abstracting of periodical information, which was subsequently purchased by EBSCO Industries, Inc. Mr. Collins has overseen the explosive growth that has taken EBSCO from a niche provider of print indexes in the 1980s to what is today one of the world's most important for-fee internet research services. He has guided the company to very strong organic growth, combined with a steady stream of over fifty strategic acquisitions. EBSCO Information Services (EBSCO) is now the leading online research service serving educational institutions and public libraries, offering the most used abstract/index and full text databases in the world. Over the last several years, EBSCO has expanded its product offerings and is now a leading eBook aggregator, discovery service provider, and point of care content provider to medical institutions. In July 2014, Tim Collins became President and CEO of EBSCO Industries, Inc., one the largest private companies in the United States, with more than five thousand employees and almost 2.5 billion dollars in annual revenue.
\end{abstract}

